\title{
LATIM, MOINHOS E CAVALEIROS ANDANTES
}

\author{
JOÃO BASTISTA TOLEDO PRADO \\ Universidade Estadual Paulista
}

"El conocimiento del latin es, por consiguiente, necesario a toda persona culta, ya por razones historicas, de saber o religiosas; y esta necesidad se convierte en imprescindible obligación para los aspirantes al sacerdocio."

(Schnitzler, 1936, p. 5)

Resumo: O texto procura identificar e analisar os equivocos dos principais tipos de argumentos que o latim sempre recebeu de seus defensores humanistas e, ao mesmo tempo, mostrar que argumentos deveriam ser utilizados para explicar as razōes que há para estudar-se a lingua de Roma com o moderno embasamento lingüistico.

Palavras-chave: humanismo; lingülstica aplicada; ensino de latim.

Desde a época em que o ensino de latim atingiu o apogeu de seu prestígio, até (e mesmo depois) os anos de seu declínio e desaparecimento, total ou parcial, na escola média do Brasil e da Europa, jamais faltaram clamores em favor das vastlssimas virtudes da língua, que a fizeram sobressair dentre as demais como um sistema perfeito, de que se valeram homens de mármore, verdadeiros deuses, pináculos da retórica e da poesia, para engendrar comunicação e, assim, através de sua história de conquistas espirituais e materiais, e dos documentos sobreviventes ao homens que os produziram, plantar as sementes do mundo na metade ocidental do planeta.

Os argumentos dos que sairam em defesa do latim - em geral professores e estudiosos apaixonados e inteiramente devotados à sua disciplina - são inúmeros e nuançados dos mais variados tons.

H. Schnitzler, o autor do trecho utilizado como epigrafe deste texto, por exemplo, aponta a erudição e o interesse religioso como motivos básicos que justificam o ensino-aprendizagem de latim.

C. Pastorino também arrola alguns argumentos em defesa do latim, os quais poderiam ser resumidos pela idéia central do desenvolvimento do racioclnio: são eles: a) ganho intelectual; b) lucro para o raciocínio; c) o exercicio da lógica prática. $O$ autor acrescenta ainda uma vantagem adicional que 0 aprendizado de latim fornece ao estudante: "habitua o aluno a construir silogismos, fáceis, é verdade, mas nem por isso menos úteis, sem necessidade sequer de saber o que é um silogismo" (Pastorino, 1948, p. 8).

Não menos notável é também o relato feito por Napoleão Mendes de Almeida do conteúdo de um oficio, encaminhado ao Ministro da Educação por três professores de universidades italianas contratados para lecionar na USP - São Paulo (Gleb Wathagin, professor de mecânica racional e mecânica celeste: Giacomo Albanese, da área de matemática; Luigi Fantapié, de análise matemática; não se menciona 0 ano de suas contratações), cujo texto, parcialmente 
reproduzido a seguir, elucida o que alunos pertencentes a outras áreas do conhecimento, que não as letras, podem esperar do estudo de latim:

"Chegados ao Brasil, ficamos admirados com o caudal de fórmulas decoradas de matemática com que os estudantes brasileiros deixam o curso secundário, fórmulas que, na Itália, são ensinadas só no segundo ano de faculdade; ficamos, porém, chocados com a pobreza de raciocínio, com a falta de ilação dos estudantes brasileiros; pedimos a vossa excelência que na reforma que se projeta se de menos matemática e MAIS LATIM no curso secundário, para que possamos ensinar matemática no curso superior". (Almeida, 1958, p. 7).

Napoleão Mendes de Almeida, concordando com as preocupaçōes dos três professores italianos, aduz seus próprios e concretos motivos para o estudo do latim: a) aguçamento do intelecto; b) ampliação da capacidade de observação: c) aperfeiçoamento do poder de concentração do espírito; d) compromisso maior com a atenção; e) desenvolvimento do espírito analítico, e f) adequação à alma e à ponderação (cf. Almeida, 1958, p. 8).

Impossivel deixar de notar que, em todo o rosário de justificativas para a existência dos estudos latinos, constantes nos manuais de ensino dessa discipłina, os argumentos são construidos com base num suposto e vago interesse extrínseco do latim para a aquisição de competências solicitadas por outras disciplinas - que podem nem sequer ter algo a ver com as ciências humanas -, por contingências sociais ou ainda pelo desejo egoísta de ampliar os conhecimentos do individuo, sem qualquer comprometimento com causas de alcance coletivo.

Quando Schnitzler diz ser o latim imprescindível para somar galardōes à galeria de troféus colecionados pelo individuo culto, não está falando de um sistema lingüistico, utilizado por um povo que viveu num certo momento da história, e que dele se serviu para exteriorizar seu psiquismo e, por isso, vale a pena ser estudado, e sim de uma espécie de medalha ou emblema ou, ainda, de um conjunto de frases lapidares que, quando sacadas, num repente, da memória (ou de uma das mangas!?) possibilita o acesso à elite dos cfrculos intelectuais. Quando fala da imperiosa necessidade de saber latim, que sentem os aspirantes ao sacerdócio e religiosos em geral, nāo objetiva a língua de Roma, mas um código artificial de palavras-de-passe, sem o que não se obtém (ou não se obtinha) mobilidade nos vários niveis de cultura da cristandade.

O ganho intelectual, o lucro para o raciocínio e o exercício da lógica prática, que Pastorino alega serem obtidos por intermédio do estudo do latim, são indubitavelmente dignos objetivos a serem perseguidos por todo aquele que pretende se dedicar com sinceridade às ciências, contudo, se ao invés de se debruçar sobre a área do conhecimento escolhida e estudá-la com afinco, se quiser valer de artiffcios para conseguir esses valiosos dividendos do esforço intelectual, por que estudar LATIM? Por que não o grego ou o sânscrito, ou o aramaico, se for verdade que tais linguas oferecem tantas ou maiores dificuldades e oportunidades à prática da ginástica mental que treina e desenvolve a mente dos estudantes, de acordo com Pastorino e vários outros? Ou, ainda, por que não se dedicar ao estudo de outro mito: o jogo de xadrez, tão celebrado por poder proporcionar a seus jogadores algo do cobiçado adestramento da lógica e da concentração?

A verdade é que as línguas e culturas dos povos (e também o jogo de xadrez!) nāo são instrumentos de ampliação da capacidade mental (mesmo que contribuam até certo ponto para isso); caso contrário, seria o mesmo que dizer que o latim (ou o grego ou o sânscrito, etc) estão ai com semelhante propósito do de um desses métodos de leitura dinâmica e melhora da concentração e da memória, tăo familiares a nós nos dias de hoje. 
Mais curioso ainda é o ofício dos três professores italianos, que pede "menos matemática e mais latim no curso secundário" com o intuito de poderem eles ensinar matemática na faculdade. O que os motivos a encaminhar ofício ao Ministro da Educação foi o fato de os alunos da graduação em matemática terem adestrado a memória (decorando fórmulas) no secundário e não a habilidade do raciocínio autônomo e de abstração. Para isso a panacéia universal parece ser o latim. Se puderam pôr à prova a sugestão dos mestres italianos, qual não deve ter sido sua decepçāo, uma vez que o ensino de latim no curso secundário sempre se baseou em métodos que exigiam doses maciças de memória mecânica de seus alunos; resultado provável: estudantes atulhados de fórmulas matemáticas sabidas de memória $e$ de listas de declinaçōes, desinências verbais, etc., ainda sem serem capazes de pensar com autonomia.

Pode-se extrair um elemento essencial do que foi dito até aqui e, dele, uma inelutável conciusāo:

- das razões usualmente apontadas para estudar-se latim, como as examinadas há pouco, nenhuma pôde encontrar na própria língua, concebida como sistema lingüístico único e diferenciado, e na cultura que the deu suporte, entendida como cabedal de experiências singulares, porém transferiveis através de toda a literatura e, por conseguinte, da língua, motivos bastantes para que exista um estudo de latim em qualquer nivel do aprendizado, sem ser necessário recorrer a estratégias.

O que gerou, difundiu e realimentou a idéia de um latim "instrumental" (no sentido de "meio através do qual se pode..."), por paradoxal que pareça, foi o próprio ensino de latim, que com suas listas de declinações, listas de vocabulário, listas de desinências verbais, etc., the criou uma imagem de código secreto, de sistema artificial, impossivel de ser entendido como língua natural de comunicação entre seres históricos, cujas limitações humanas impediriam aprender e utilizar, por vias comuns, um sistema tão complexo e rigoroso; seres cujas necessidades mais imediatas simplesmente não poderiam ser exprimidas naquela lingua (se é que é uma língua, pensariam eles) afeita só aos mais altaneiros discursos, só às mais ousadas aventuras do pensamento, so às mais belas e proverbiais frases.

Dessa forma, se se quer um latim livre de argumentos incertos e de mistificações, se se quer um latim cujo prestlgio independa da solicitação constante de defensores entusiasmados, se se quer um latim honesto que valha a pena ser estudado sem excruciar e atemorizar os alunos, já tão naturalmente inseguros acerca do porque das coisas, é preciso um método de ensino que valorize a lingua pelo que ela é, sem máscaras, e que se baseie nos elementos mais concretos do sistema, organizados racionalmente, sem sobrecarga para a memória, mas que também possam ser automatizados pelo hábito de seu emprego em exercicios de reenunciação de frases latinas (e nāo através de frases ad hoc).

Longe de tecer críticas sem propor soluções, pensamos que tal feito esteja ao alcance de todos os que se ocupam do latim, professores e alunos, através da valorização do estudo do significante latino e de suas constantes, como se demonstrará a seguir, no texto do Prof. Haroldo Bruno. 


\section{ABSTRACT:}

This text seeks to identify and analyse the misunderstandings of the main kinds of arguments which Latim has always received from its humanist defenders and, at the same time, it seeks to show what arguments should be used to explain the reasons for studying that idiom of the ancient Rome by using the modern linguistic applications.

\section{REFERÊNCIAS BIBLIOGRÁFICAS:}

ALMEIDA, Napoleão Mendes de. Noções fundamentais de lingua latina. São Paulo: Saraiva 1958.

PASTORINO, C. T. A chave da versāo latina. Complementos à gramática latina para facilitar o estudo aos alunos do curso ginasial. Rio de Janeiro: Imprensa Nacional, 1947.

SCHNITZLER, H. Nuevo método para aprender el latin. Friburgo de Brisgovia: Herder \& Cia, 1936. 